\title{
Conversion of IgM to IgG by Lysates of Burkitt's Lymphoma Cells
}

\author{
Robert E Bases $^{1 *}$, Rukmani Lekhraj ${ }^{2}$, Seema Gollamudi' ${ }^{2}$, Scott J Garforth ${ }^{3}$, Jennifer T Aguilan ${ }^{4}$ and Edward Nieves ${ }^{5}$ \\ ${ }^{1}$ Departments of Radiology, Radiation Oncology, Neurosurgery, Albert Einstein College of Medicine, Montefiore Medical Center, Bronx, NY 10467, USA \\ ${ }^{2}$ Department of Neurosurgery, Montefiore Medical Center, Bronx, NY 10467, USA \\ ${ }^{3}$ Macromolecular Therapeutics Facility, Albert Einstein College of Medicine, 1301 Morris Park Avenue, Bronx, NY 10461, USA \\ ${ }^{4}$ Department of Pathology, Albert Einstein College of Medicine, Bronx, NY 10461, USA \\ ${ }^{5}$ Department of Biochemistry, Albert Einstein College of Medicine, Bronx, NY 10461, USA
}

${ }^{*}$ Corresponding author: Robert E Bases, Departments of Radiology, Radiation Oncology, Neurosurgery, Albert Einstein College of Medicine, Montefiore Medical Center, Bronx, NY 10467, USA; Tel: 914.633.7766; Email: rbases@verizon.net

Received: March 04, 2021; Accepted: March 15, 2021; Published: March 24, 2021

\begin{abstract}
The immune response progresses by the dissociation of IgM to component IgG's. What are the factors which guide the maturation? Cell lysates of Burkitt's lymphoma cells (CRL-1647) strongly reduced IgM to smaller subunits, including those of IgG size with the antigenic identities of IgG. Sepharose column fractionation found them in size classes of $5 \mathrm{kDa}$ to $20 \mathrm{kDa}$. Further identification of their components may give clues to therapeutic opportunities in the treatment of patients with hyperglobulinemias might result. Do patients lack the factors in $5 \mathrm{kDa}$ to $20 \mathrm{kDa}$ fractions or are their IgM's deficient in receptors? Do B cells from normal subject contain such factors?
\end{abstract}

\section{Introduction}

The important landmark results of [1] showed that the IgM pentamer is an asymmetrical pentagon with an open groove that binds specific (AIM) protein. It contains one large gap. Other proteins could also bind in this way, perhaps leading to the evolution of single, ie. IgG, species. Here we examined the effects on IgM of protein and cell lysates of a leukemic cell line, CRL-1647. Lysates from 1.5 X 108 cells were fractionated on Sepharose. The different size fractions were incubated with exogenous IgM to determine which ones could release immunopositive species, determined in Western blot analysis. IgG like proteins $\sim 150 \mathrm{kDa}$ and immunoreactive to IgG were released by fractions in the size range of $20 \mathrm{kDa}$ to $5 \mathrm{kDa}$. When the fractions were incubated without exogenous IgM, IgG release was not found. Some IgG was found in the $150,000 \mathrm{MW}$ size fraction with or without incubation, as expected, because the crude lysates contain endogeous IgG as well as IgM.

Mass spectroscopy analysis of the $20 \mathrm{kDa}$ to $5 \mathrm{kDa}$ fractions showed that they contained immunoproteins, as well as some proteins with catalytic activity, perhaps responsible for release of IgG from IgM. These experiments may provide clues to cell mechanisms responsible for the increased content of IgG found in Burkitt's lymphoma cells after lucanthone and ionizing radiation treatment $[2,3]$. Incubation of exogenous or endogenous IgM with partially purified cell lysates released IgG immunopositive species. Presumably, proteases were responsible for the conversion of the IgM pentamers to IgG monomers, multimers, and fragments. Sepharose fractionation showed that active factor or factors in the conversion resided in $20 \mathrm{kDa}$ to $5 \mathrm{kDa}$ size classes. No detectable IgG was released when these fractions were incubated alone or without IgM. Small specific immunoglobulins were present in these Sepharose fractions, as determined by mass spectroscopy, but they are not known to be a factor in release of IgG. The factors described here might have relevance for certain hematological disorders, such as Waldenstrom's macroglobulinemia. These patients have abundant serum IgM but little or no IgG. Is there a deficiency of factors such as those described here or are there IgM structural abnormalities in their IgM which render it refractory to normal factors?

\section{Results}

Experiments of Figures 1 and 2 showed that factors in lysates of CRL-1647 Burkitt's lymphoma cells released IgG fragments, upon incubation with IgM. Purified IgM from a multiple myeloma patient or endogenous IgM from the Burkitt's lymphoma cells served as substrates.

Sepharose fractionation of the lysate showed that the release factors were mostly in $20 \mathrm{kDa}$ to $5 \mathrm{kDa}$ fractions (Figure 3). Some endogenous IgG was found in 250 to $110 \mathrm{kDa}$ fractions and a high molecular weight fraction $>5000 \mathrm{kDa}$, contributed immunoglobulin specific protein, but were not studied further. The identity of release fractions $\mathrm{B} 6$ and $\mathrm{B} 5(20 \mathrm{kDa}$ to $5 \mathrm{kDa})$ is to be the subject of further studies. So far, the immunoglobulin M-degrading enzyme of Streptococcus suis is the only known protease cleaving the IgM multimer specifically [4]. 


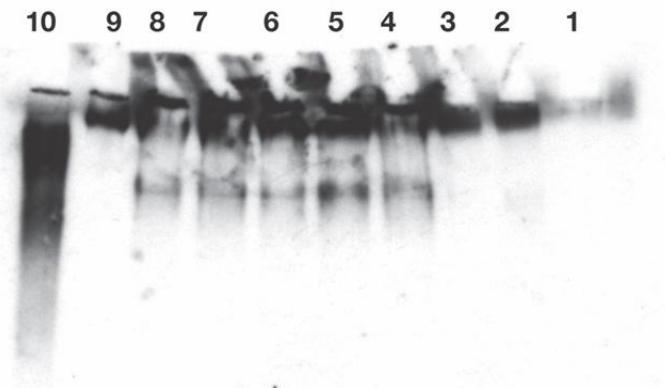

Figure 1: Release of IgG reactive protein from exogenous substrate IgM was found in lanes 4-8. Enhancement of release by cell treatment with lucanthone (lanes 6 and 7) or radiation (lane 8) was not found, as with endogenous IgM (Ref \#2) without further incubation. The released reactive species were not polydisperse, therefore, suggesting a specific attack on IgM. Release of IgG fragments from exogenous human myeloma IgM by lysates of Burkitt's lymphoma cells. Cell lysates were prepared from 3.5 X 107 cells. Lysate contained 0.3 $\mathrm{mg} / \mathrm{ml}$ in $1 \mathrm{ml}$ final volume, followed by Western blot analysis, as in published Methods, appended. Twenty second exposure of the film.

Lane 1: No lysate. Lane 2: $5 \mu \mathrm{L}$ of cell lysate incubated at $0^{\circ} \mathrm{C}$ for 50 minutes without exogenous IgM. Lane $3: 5 \mu \mathrm{L}$ of cell lysate were incubated at $37^{\circ} \mathrm{C}$ for 50 minutes without exogenous IgM. Lanes 4 and 5: $5 \mu \mathrm{L}$ of cell lysate incubated at $37^{\circ} \mathrm{C}$ for 50 minutes with $10 \mu \mathrm{L}$ containing $0.45 \mu \mathrm{g}$ of exogenous IgM. $10 \mu \mathrm{L}$ of neutral loading buffer was added. Lanes 6 and 7: $5 \mu \mathrm{L}$ from lucanthone treated cells were incubated at $37^{\circ} \mathrm{C}$ for $50 \mathrm{~min}$. with $10 \mu \mathrm{L}$ containing $0.45 \mu \mathrm{g}$ of exogenous IgM, as above, before loading. Lane 8: $5 \mu \mathrm{L}$ of cell lysate from cells taken 2 days after $10 \mathrm{~Gy}$ were incubated $50 \mathrm{~min}$ at $37^{\circ} \mathrm{C}$ with $0.45 \mu \mathrm{g}$ of exogenous IgM. Lane 9: $0.45 \mu \mathrm{g}$ of exogenous IgM in PBS (Fisher: myeloma monoclonal). Lane 10: $0.1 \mu \mathrm{g}$ of IgG (Biolegend ultraleaf). Western blots were developed from a film exposed for 20 seconds (lanes-4-10). Endogenous IgM and IgG were only detectable after 10 minute exposures. Experiment was repeated twice.

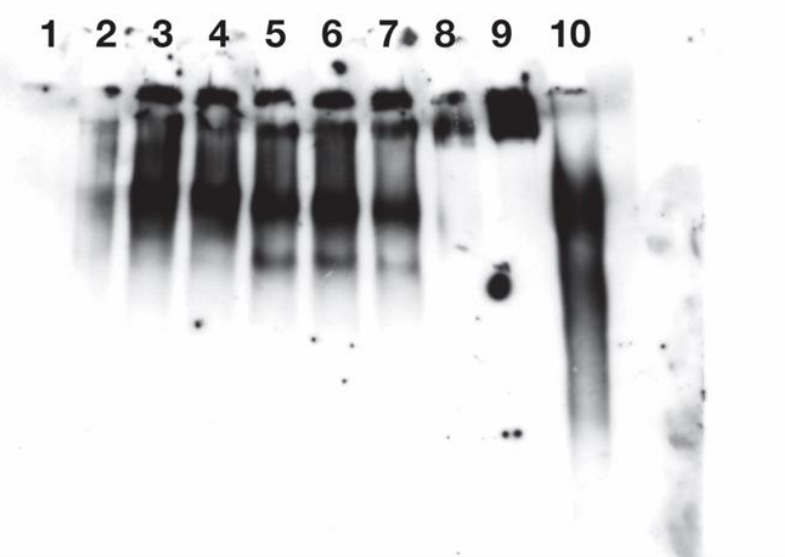

Figure 2: Release of IgG immuno positive species from endogenous IgM of Burkitt's lymphoma cells CR2-1647 by lysate from those cells.

Cell lysates isolated from 1.5 X 108 CRL-1647 cells were prepared in a final volume of 1 $\mathrm{ml}$, as described in Methods. Exogenous IgM was not added to the lysate. The film was exposed for 4 minutes. The lysate protein content was $0.865 \mathrm{mg} / \mathrm{ml}$.

IgG immunoreactive species were found in near the origins in lanes 2-7 and, as expected, in lanes 9 and 10. But released fractions were found; greater in lanes 5, 6, 7, containing $37^{\circ} \mathrm{C}$ incubated lysate material than in lanes $2,3,4$, containing lysate material held at $0^{\circ} \mathrm{C}$. The faster anti IgG reactive material of lanes 5,6 , 7 were significantly more abundant than corresponding material in lanes $2,3,4$ (p less than 0.029 ).

Lane 1: No cell lysate, mobility standards. Lanes $2,3,4: 0.2 \mu \mathrm{g} /$ well of lysate incubated 1 hour at $0^{\circ} \mathrm{C}$. Lanes $5,6,7$ : each received $0.32 \mu \mathrm{g} /$ well of lysate incubated 1 hour at $37^{\circ} \mathrm{C}$. Lane 8: no lysate added. Lane 9: $0.45 \mu \mathrm{g}$ of exogenous human myeloma lgM. Lane 10: 0.1 $\mu \mathrm{g}$ of human IgG standard (Biolegend ultraleaf). One ml of lysate from 1.5 X 108 CRL1647 cells (not supplemented with IgM) contained:

Total protein: $865 \mu \mathrm{g}$.

IgM: $65 \mu \mathrm{g}$.

Faster IgG: $0.034 \mu \mathrm{g}$ from lysate incubated $1 \mathrm{~h}$ at $0^{\circ} \mathrm{C}$

Faster IgG: $0.11 \mu \mathrm{g}$ from lysate incubated $1 \mathrm{~h}$ at $37^{\circ} \mathrm{C}$

These values were determined from corresponding lanes of Western blot, as shown here and from other exposures of the Western blots not shown.

Results with lysates in these studies demonstrate their ability to release $\operatorname{IgG}$ reactive material from IgM. Interference from unknown sources in the lysates was encountered in many other experiments and in those of Figures 2. Column purification and fractionation was needed for characterization of the lysate fractions. Experiment was repeated twice.
The IgM pentamers appears to be an asymmetric pentagon with an open groove that binds the AIM protein, an apoptosis inhibitor of macrophage [5]. Other proteins may bind there and then digest IgM structures. IgG's released by cell lysates in some experiments

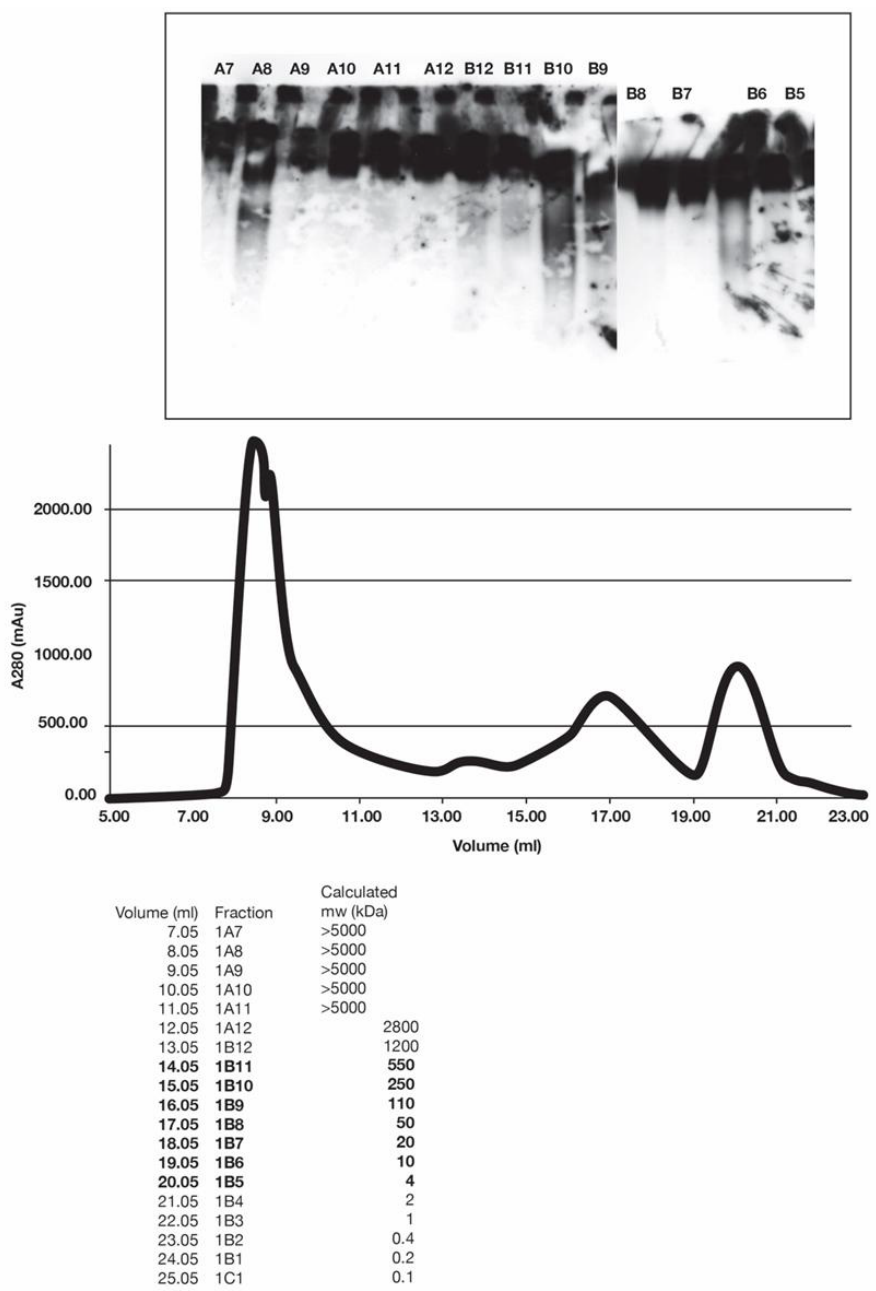

Figure 3: Endogenous IgG was found in fraction B 10, a reference standard here. When incubated with IgM, fraction B6 was able to release IgG reactive species. Some IgG reactive material was associated with fraction A8, of unknown significance.

Gel filtration standards (BioRad) in a volume of $1 \mathrm{ml}$ were injected into a Superose 6 Increase 10/300 GL (GE Life Sciences) in $50 \mathrm{mM}$ Tris; pH 8.0, $0.1 \mathrm{M} \mathrm{NaCl}, 1 \mathrm{mM}$ EDTA. The chromatogram was used to approximately calibrate the column for the analysis of Burkitt's Lymphoma (CRL-1647) also injected in a volume of $1 \mathrm{ml}$

The fractions in brackets correspond to the range of molecular weights that are within the range of our gel filtration markers.

Each well received $10 \mu \mathrm{L}$ of Sepharose fraction and $10 \mu \mathrm{L}$ of IgM. After incubation, 10 $\mu \mathrm{l}$ of loading buffer was added. The approximate molecular weight of protein in each fraction was calculated from the volume measurement at the beginning of each fraction. For example, fraction B- 11 contains proteins in the range of $250-500 \mathrm{kDa}$. IgG was found in fractions B 10.

FRACTION B6 contained factors or a factor which caused release of IgG, (reactive with anti $\operatorname{IgG}$ ) when incubated with IgM. Without IgM no incubation of the fraction failed to release detectable IgG.

Endogenous IgG was found in fraction B 10, a reference standard here. When incubated with $\operatorname{lgM}$, fraction B6 was able to release IgG reactive species. Some IgG reactive material was associated with fraction A8, of unknown significance.

Gel filtration standards (BioRad) in a volume of $1 \mathrm{ml}$ were injected into a Superose 6 Increase 10/300 GL (GE Life Sciences) in $50 \mathrm{mM}$ Tris; pH 8.0, 0.1 M NaCl, 1 mM EDTA. The chromatogram was used to approximately calibrate the column for the analysis of Burkitt's Lymphoma (CRL-1647), also injected in a volume of $1 \mathrm{ml}$. A gel filtration separation was made of $1 \mathrm{mg}$ of lysate of CRL-164 7 cells. Endogenous IgM and IgG are found in these lysates. Experiment was repeated twice. 
were between $150 \mathrm{kDa}$ and $250 \mathrm{kDa}$ (Figure 4). Presumably, some IgG protein monomers were released from the IgM pentamers with some remnant IgG proteins still attached to the monomers. Much immunopositive material from cell lysates migrated between the mobility of IgM and IgG. This may be due to incomplete digestion and release of IgG from pentamers, i.e. as fragments larger than IgG monomers. Self aggregation of $150 \mathrm{kDa}$ IgG-like proteins might account for slower migration of considerable IgG immunopositive species. Self aggregation of the IgG standards also was found. The IgG standard in gels resembles the IgG species that was released from IgM (Figures 4-6).

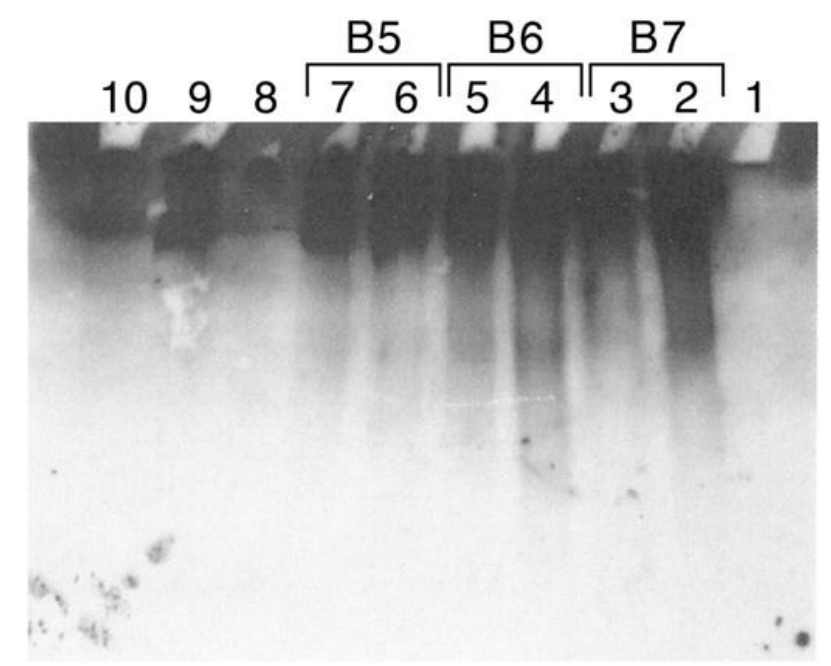

Figure 4: Sepharose fractionation of CRL 1647 lysates from a second harvest of CRL 1647 cells.

B5, B6, B7, released IgG reactive material, confirming results of Figure 2.

Release of IgG from exogenous IgM by Sepharose fractions, 4 to $20 \mathrm{kDa}$, from CRL 1647 lysate. Anti lgG antibody stained.

Lane 1: MW markers. Lanes 2, 3: $10 \mu \mathrm{L}$ of Fraction B7 of Figure 4 incubated at $37^{\circ} \mathrm{C}$ with $0.45 \mu \mathrm{g}$ of IgM. Lane $4,5: 10 \mu \mathrm{L}$ of fraction B6 of Figure 4 incubated at $37^{\circ} \mathrm{C}$ with $0.45 \mu \mathrm{g}$ of $\operatorname{lgM}$. Lane 6, 7: $10 \mu \mathrm{L}$ of fraction $\mathrm{B} 5$ of Figure 4 incubated at $37^{\circ} \mathrm{C}$ with $0.45 \mu \mathrm{g}$ of $\operatorname{lgM}$. Lane 8 : No lysate. Lane 9: IgM. Lane 10: IgG $(0.45 \mu \mathrm{g}) 0.1 \mu \mathrm{g}$. Experiment was repeated three times.

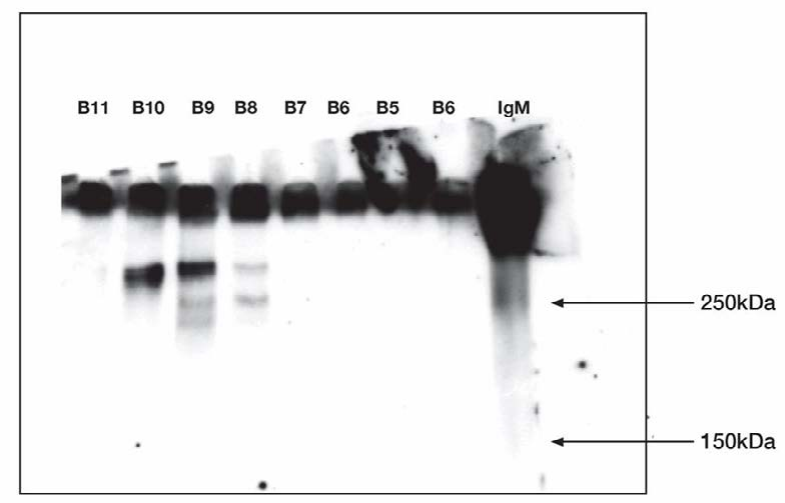

Figure 5: Western Blot.

$\mathrm{B} 5, \mathrm{~B} 6$ did not release IgG reactive material when $\operatorname{IgM}$ was not included in the incubation. Test of fractions incubated without IgM at $37^{\circ} \mathrm{C} 1 \mathrm{~h}$. Refer to figure 3 for Sepharose fractions.

Anti IgG antibody stained.

Molecular weight markers: $10 \mu \mathrm{L}$ fraction B11; $10 \mu \mathrm{L}$ fraction B10; $10 \mu \mathrm{L}$ fraction B9; 10 $\mu \mathrm{L}$ fraction $\mathrm{B} 8 ; 10 \mu \mathrm{L}$ fraction $\mathrm{B} 7 ; 10 \mu \mathrm{L}$ fraction $\mathrm{B} 6 ; 10 \mu \mathrm{L}$ fraction $\mathrm{B} 5 ; 10 \mu \mathrm{L}$ fraction $\mathrm{B} 6$; $10 \mu \mathrm{L}$ fraction IgM $0.45 \mu \mathrm{g}$ standard. Experiment was repeated twice.

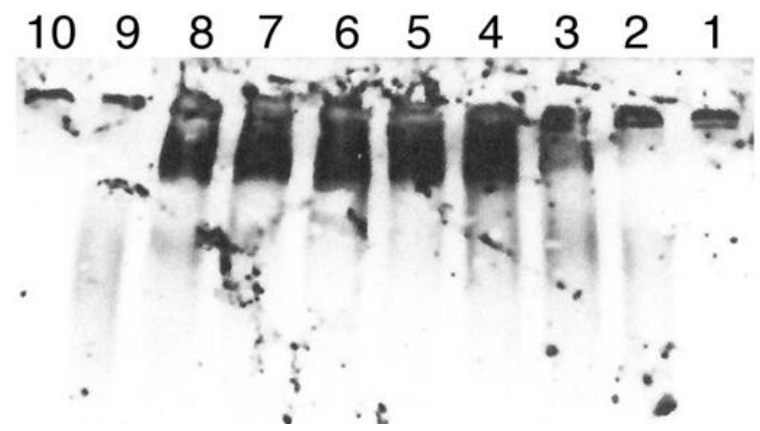

Figure 6: Digestion of IgM by another preparation of Sepharose fractions of CRL-1647 cell lysates. The Western blot was developed at $1 / 5$ the sensitivity of the study in Figure 5. Lane 1: IgM, undigested, $0.45 \mu \mathrm{g}$. Lane 2: IgM digested by Sepharose fraction B4 Lane 3: IgM digested by Sepharose fraction B5. Land 4: IgM digested by Sepharose fraction B6. Lane 5: IgM digested by Sepharose fraction B7. Lane 6: IgM digested by Sepharose fraction B8. Lane 7: IgM digested by Sepharose fraction B9. Lane 8: IgG digested by Sepharose fraction B 10. Lane 9: IgG standard 0.1 $\mu \mathrm{g}$. Lane 10: MW standards (BioRad). $0.1 \mu \mathrm{g}$ Standard IgG shown in lane 9 is polydisperse but most of it is seen when the other species are less evident. IgG migrated more slowly than expected. The $150 \mathrm{kDa}$ and 250 $\mathrm{kDa}$ standards are faintly seen in lane 10. Inspection of lanes 3 and 4 suggests release of digestion products by Sephorose fractions 5 and 6 was greater than with other fractions. Lane 8 again indicates presence of IgG in Sepharose fraction B 10. Experiment was repeated twice.

We have identified the lysate digestion products of IgM as IgG by its immune relationship to IgG and its electrophoretic mobility (Figures 4 and 6). However, the amino acid composition of these species is needed for further definitive evaluation of them as IgG. Release of IgG immunopositive species after digestion of IgM with cell lysates exhibited in gels an array of polydisperse IgG positive entities. However, their mobility in the gels was similar to that observed with undigested $\operatorname{IgG}$ commercial standards in every study shown here. Their mobility, and that of the IgG standards were less than expected. Most of the IgG standard particles exhibited single mobility, as in lane 9 of Figure 6. The relevance of our findings of IgM sensitivity to certain $5 \mathrm{kD}$ to $20 \mathrm{kD}$ proteins should be explored, especially in patients with Waldenström's macroglobulinemia [5]. Are these patients' sera deficient?

\section{Materials and Methods}

\section{Cells}

CRL-1647 Burkitt human lymphoma cells (0 L) were purchased from American Type Culture Collection (ATCC), Manassas, VA 20108. They were grown in suspension at $37^{\circ} \mathrm{C}$ in Roswell Park Memorial Institute 1640 medium with 10\% fetal bovine serum in $8 \%$ $\mathrm{CO} 2$ in a humidified atmosphere. The cell culture doubling time was 24 hours. Media and sera were from ATCC.

\section{Cell Lysates}

Cells were sedimented from phosphate buffered saline without $\mathrm{Ca}++$ or $\mathrm{Mg}++$, resuspended in lysis buffer with $10 \mu \mathrm{M}$ Aprotinin and sonicated with 20 one-second strokes leaving 1-2\% unbroken cells. Lysates of $10^{7}$ to $10^{8}$ cells that were clarified by centrifugation @ 15,500 $\mathrm{g}$ for $12 \mathrm{~min}$ contained approximately $1 \mu \mathrm{g} / \mu \mathrm{l}$ of protein. Lysis buffer: 0.lN NaCL, lmM EDTA, 0.05 M TRIS, pH 8.0 Aprotinin $10 \mu \mathrm{M}$. 


\section{Western Blots}

For most experiments, $7 \mathrm{~cm}$ minigels, purchased from BioRad Laboratories, Los Angeles, CA were used. Buffer without SDS or methanol, containing $25 \mathrm{mM}$ Tris, $\mathrm{pH} 8.3$ and $192 \mathrm{mM}$ glycine were used for gel electrophoresis and Western blot transfer. Human IgG 1 purified Ultraleaf Isotype $1 \mu \mathrm{g} / \mathrm{ml} \mathrm{CTRL}$ was purchased from Biolegend 9727 Pacific Heights Blvd, San Diego, CA 92121. Human IgM 4.5 mg/ $\mathrm{ml}$ was purchased from Fisher Thermofisher.com (product 31146). Horseradish peroxidase $0.4 \mathrm{mg} / \mathrm{ml}$ linked donkey anti human IgG was from Biolegend.

\section{Sepharose Fractionation}

Gel filtration standards (BioRad) in a volume of $1 \mathrm{ml}$ were injected onto a Sepharose 6 Increase 10/300 GL (GE Lifesciences) in $50 \mathrm{mM}$ Tris $\mathrm{pH} 8.0,0.1 \mathrm{M} \mathrm{NaCl}, 1 \mathrm{mM}$ EDTA. The chromatogram was used to approximately calibrate the column for analysis of Burkitt's lymphoma lysate, also injected in a volume of $1 \mathrm{ml}$.

\section{Mass Spectrometry Analysis}

LC-ESI-MS/MS (liquid chromatography electrospray ionization mass spectrometry) analysis of the peptide digests was done by C18-Reversed Phase (RP) chromatography using an Ultimate 3000 RSLCnano System (ThermoScientific, USA) equipped with an Acclaim PepMap RSLC C18 column $(2 \mu \mathrm{m}, 100 \AA$ A $75 \mu \mathrm{m}$ x $15 \mathrm{~cm}$, Thermo Scientific, USA). The UPLC was connected to a TriVersa NanoMate nanoelectrospray source (Advion, USA) and a linear ion trap LTQ-XL (ThermoScientific, USA) mass spectrometer with ESI source operated in the positive ionization mode. The MGF files generated from the raw LC-ESI-MS/MS data were searched by Mascot (version 2.5, Matrix Science, USA) against Swissprot AC database version 2016-05 (551,193 protein sequences) with the following search parameters: trypsin; two missed cleavages; peptide charges of +2 and +3 ; peptide tolerance of $2.5 \mathrm{Da}$; MS/MS tolerance of 0.8 $\mathrm{Da}$; carbamidomethylation (Cys) for fixed modification; deamidation (Asn and Gin) and oxidation (Met) for variable modifications. A decoy database search was also performed to measure false discovery rate. The Mascot search results were validated by Scaffold version 4.1.1 (Proteome Software Inc., USA).

\section{References}

1. Hiramoto E, Tsutsumi A, Suzuki R, Matsuoka S, Arai S, et al. The lgM pentamer is an asymmetric pantagon with an open groove that binds the AIM protein. Science Advances 4 eaau 1199.

2. Bases R, Lekhraj R, Tang X, Huang JZ, Duan Z, et al. (2014) Enhanced content of IgG in Burkitt's lymphoma cells after treatment with the topoisomerase II inhibitor, lucanthone. J Bioanal Biomed 9: 186-193.

3. Bases R, Lekhraj R (2018) Ionizing Radiation and Lucanthone Enhance the IgG content of Burkitt's lymphoma cells. J Bioanal Biomed 10: 105-107.

4. Seele J, Beineke A, Hillermann LM, Jaschok B -Kentner, von Pauvel-Rammingen W, et al. (2015) The Immunoglobulin M-degrading enzyme of Streptococcus suis, ldessuis is involved in complement evasion. Veterinary Research 46: 45-59.

5. Tedeschi A, Conticello kC, Rizzi R, Benevolo G, Laurenti kL, et al. (2019) Diagnostic framing of IgM monocolonal gammopathy: focus on Waldenström's macroglobulinemia. Hematological Oncology 37: 117-128. 